Konstantin Neumann

Thomas Oellerich

Henning Urlaub

ürgen Wienands

\section{The B-lymphoid Grb2 interaction} code

\author{
Authors' addresses \\ Konstantin Neumann ${ }^{1}$, Thomas Oellerich ${ }^{1}$, Henning Urlaub ${ }^{2}$, Jürgen \\ Wienands ${ }^{1}$ \\ ${ }^{1}$ Institute of Cellular and Molecular Immunology, Georg \\ August University of Göttingen, Göttingen, Germany. \\ ${ }^{2}$ Max Planck Institute of Biophysical Chemistry, Bioanalytical \\ Mass Spectrometry Group, Göttingen, Germany. \\ Correspondence to: \\ Jürgen Wienands \\ Georg August University of Göttingen \\ Institute of Cellular and Molecular Immunology \\ Humboldtallee 34, 37073 Göttingen, Germany \\ Tel.: +490551395812 \\ Fax: +490551395843 \\ e-mail: jwienan@uni-goettingen.de \\ Acknowledgements \\ Work from our laboratory is supported by the Deutsche \\ Forschungsgemeinschaft through FOR 521 and the European \\ Community through PADnet.
}

Immunological Reviews 2009

Vol. 232: 135-149

Printed in Singapore. All rights reserved

(C) 2009 John Wiley \& Sons $A / S$

Immunological Reviews

0105-2896
Summary: The growth factor receptor-bound protein 2 (Grb2) is a ubiquitously expressed and evolutionary conserved adapter protein possessing a plethora of described interaction partners for the regulation of signal transduction. In B lymphocytes, the Grb2-mediated scaffolding function controls the assembly and subcellular targeting of activating as well as inhibitory signalosomes in response to ligation of the antigen receptor. Also, integration of simultaneous signals from B-cell coreceptors that amplify or attenuate antigen receptor signal output relies on Grb2. Hence, Grb2 is an essential signal integrator. The key question remains, however, of how pathway specificity can be maintained during signal homeostasis critically required for the balance between immune cell activation and tolerance induction. Here, we summarize the molecular network of Grb2 in B cells and introduce a proteomic approach to elucidate the interactome of Grb2 in vivo.

Keywords: B-cell activation, adapter proteins, SH2 and SH3 domains, protein tyrosine kinases, lipid phosphatases

\section{Introduction: a brief historical perspective on Grb2 structure and function}

The discovery of adapter proteins and the elucidation of their role in signal transduction are intrinsically tied to the scientific history of oncogenes. In fact, a hallmark in the understanding of neoplastic cell transformation and human oncogenesis was the identification and molecular cloning of enzymatically inert adapter proteins as proximal effectors for cell surface receptors with intrinsic protein tyrosine kinase activity. Lowenstein et al. (1) used a biochemical approach to globally purify proteins that can bind to the tyrosine-phosphorylated forms of the epidermal growth factor receptor (EGFR) or the platelet-derived growth factor receptor. Several candidate proteins were identified and accordingly numbered. The growth factor receptorbound protein 2 (Grb2) was found to be entirely composed of non-catalytic protein-protein interaction modules, which were previously recognized as evolutionary conserved building blocks of Src-family kinases and hence named Src homology (SH) domains (2). In a cDNA library screen for mammalian genes encoding SH2 domain-containing proteins, Matuoka et al. (3) independently identified Grb2 as a molecule 
called Ash for 'abundant Src homology'. Grb2 encompasses one central SH2 domain flanked on either side by one SH3 domain. SH2 and SH3 domains can bind to short consensus peptide motifs which harbor a phosphorylated tyrosine residue or a proline-rich recognition site with a PXXP core, respectively (4). The cognate ligand can be recognized by the $\mathrm{SH} 2$ or the SH3 domain in cis as well as in trans allowing for intra- and intermolecular interactions.

The binding preferences of the Grb2 domains have been extensively studied in many cellular systems. The consensus motif for the Grb2 SH2 domain requires an asparagine (5) and prefers a methionine (6) in the phosphotyrosine +2 and +3 position, respectively. Moreover, under conditions where different SH2 domains compete for binding (as it is the case in the live cell), only the Grb2 SH2 domain tolerated a positively charged arginine residue in the +1 position of the negatively charged phosphotyrosine (6). Hence, a highly selective ligand for the Grb2 SH2 domain is pYRNM. The N-terminal SH3 domain has been shown to interact with a typical polyproline helix motif encompassing a PxxPxR sequence $(7,8)$, An atypical motif, PXXXR/KXXKP, lacking the classical PXXP core is bound with high affinity by the C-terminal SH3 domain of Grb2 with a remarkable versatility (9, 10). Many of the reported ligand proteins associate with Grb2 in vivo through a concerted action of the Grb2 domains in a constitutive and stimulation-dependent manner. The structure of fulllength Grb2 was determined by X-ray crystallography at $3.1 \AA$ (11) as well as in solution by nuclear magnetic resonance spectroscopy and small angle X-ray scattering measurements (12). The crystal structure shows a compactly folded protein with intramolecular contacts between the SH3 domains. In solution, Grb2 exhibits extensive flexibility facilitating ligand recognition.

The Grb2 architecture is highly conserved during evolution. Dependent on the species from which it is isolated, Grb2 migrates in conventional gel electrophoresis with an apparent molecular mass of 25-30 kDa. While Grb2 is ubiquitously expressed, the Grb2-related adapter protein (Grap), which shares almost $60 \%$ amino acid sequence identity to Grb2, is predominantly but not exclusively expressed in spleen and thymus (13). A hematopoietic cell type-specific expression pattern is reported for the third Grb2 family member, Grb2-related adapter downstream of Shc (Gads) (14). Gads is alternatively called GrpL (Grb2-related protein of the lymphoid system) (15), Mona (monocytic adapter)(16), GRID (Grb2-related protein with insert domain) (17), Grf40 (Grb2 family member of $40 \mathrm{kDa}$ ) (18), or Grap-2 (19).
An early key to the understanding of a major Grb2 function was its striking structural similarity to the product of the Caenorhabditis elegans gene Sem-5, which together with Let-23 (encoding an EGFR-like protein) and Let-60 (encoding a p21Ras-like protein) controls vulval induction during nematode development $(1,3,20)$. Another line of evidence supporting that Grb2 is directly involved signal transduction from cell surface receptors to the Ras pathway came from studies on a homeotic gene in Drosophila called sevenless. Loss of sevenless function abrogated development of the R7 photoreceptor in the compound eye of the insect (21). Sevenless turned out to encode a transmembrane receptor with intrinsic tyrosine kinase activity (22), and its effector Drk (downstream of receptor kinase) was identified as the Drosophila homologue of Sem-5/Grb2 (23, 24). Landmark publications in 1993 (23-30) ultimately unraveled a basic mechanism of how receptor tyrosine kinases can trigger Ras activation via the conserved SH2/SH3 domain-containing linker Grb2/Sem-5/ Drk. Ligand-induced crosslinking of the surface receptor stimulates trans-phosphorylation on tyrosine residues in the cytoplasmic receptor domains leading to the $\mathrm{SH} 2$ domainmediated recruitment of cytosolic Grb2, which is itself constitutively complexed via its two $\mathrm{SH} 3$ domains to a guanine nucleotide exchange factor (GEF) called son of sevenless (SOS). The stimulation-dependent membrane translocation process targets SOS into the vicinity of its substrate p21Ras, which is tethered to the inner leaflet of the plasma membrane via post-translational lipid modifications (31). SOS-mediated exchange of GDP for GTP activates Ras. Notably, human Grb2 and Drosophila Drk can functionally replace Sem-5 signaling in C. elegans (32). A variation on this common theme is the additional inclusion of another $\mathrm{SH} 2$-containing adapter protein called SHC (33). Here, it is SHC that binds to the phosphorylated receptor tail through its N-terminally located $\mathrm{SH} 2$ domain and subsequently recruits the Grb2/SOS complex via phosphotyrosine residues located in the central region of SHC (34). A second phosphotyrosine-binding module (PTB) is found at the C-terminal end of SHC.

It appeared a matter of time until Grb2 together with or without the help of SHC would be identified as the linker module that couples the activated B-cell antigen receptor (BCR) to SOS and subsequently to Ras. However, the BCR does not fit into the Grb2/SOS paradigm. In fact, Grb2 was found to be dispensable for BCR-induced Ras activation but to exert multiple functions implicated in activating and inhibiting B-cell activation. A comprehensive understanding of the Grb2 network in B cells is still being sought. We describe in this review the major B-cell functions of Grb2 and introduce a 
proteomic approach to elucidate in vivo interaction partners of Grb2.

\section{Grb2 and SOS are dispensable for BCR-induced Ras activation}

In contrast to cell surface receptors with intrinsic kinase activity, the BCR connects to cytoplasmic tyrosine kinases of the Src and Syk family through the immunoreceptor tyrosinebased activation motifs (ITAMs) in the BCR signaling subunits Ig- $\alpha$ and Ig- $\beta(35,36)$. Early studies revealed triggering of the Ras/Raf/MAPK pathway in response to BCR ligation (37). The likely possibility that this activation step involves the canonical Grb2/SOS module was initially supported by several observations. Crosslinking of the BCR induced tyrosine phosphorylation and membrane translocation of SHC (38-40), which can potentially interact with the phosphorylated BCR $(41,42)$ and is also found in complexes containing Grb2 and SOS (43-45). It thus came as a surprise that ablation of SOS expression by gene targeting in the DT40 B-cell line strongly compromised receptor tyrosine kinase- but not BCR-induced Ras activation (46). It is now clear that another GEF activity provided by the class of Ras guanosine nucleotide-releasing proteins (RasGRPs) (47) is predominantly responsible for Ras activation in $\mathrm{B}$ cells.

The BCR couples to RasGRPs via phospholipase C- $\gamma 2$ (PLC- $\gamma 2$ ). Activation of this enzyme is initiated by Syk bound via its tandem SH2 domains to a doubly phosphorylated ITAM. The proximal Syk substrate is the adapter SH2 domaincontaining leukocyte protein of $65 \mathrm{kDa}$ (SLP-65)/B-cell linker (BLNK) $(48,49)$. Phosphorylated SLP-65 recruits PLC- $\gamma 2$ and its upstream regulator Bruton's tyrosine kinase (Btk) into a trimolecular complex allowing for PLC- $\gamma 2$ activation and subsequent hydrolysis of membrane phospholipids into membrane-bound diacylglycerol (DAG) and soluble inositoltrisphosphate (IP3) $(50,51)$. The DAG product recruits RasGRP family members by virtue of their $\mathrm{C} 1$ domain (46, 52, 53). Full GEF activity of membrane-anchored RasGRPs is achieved upon phosphorylation on threonine residues, which requires membrane recruitment and activation of protein kinase $\mathrm{C}$ by DAG and IP3-triggered $\mathrm{Ca}^{2+}$ mobilization, respectively $(54,55)$.

B cells express RasGRP isoforms 1 and 3. RasGRP1 is recruited to the plasma membrane following $\mathrm{BCR}$ engagement $(52,56)$, and overexpression of RasGRP1 augments Ras signaling (52). However, BCR-induced Ras activation appears to be normal in RasGRP1-deficient DT40 B cells (46). By marked contrast, ablation of RasGRP3 expression almost abrogated
BCR-regulated Ras signaling in DT40 cells (46) and in mice (57). Hence, the activated BCR employs the Syk/SLP-65/ PLC- $\gamma 2$ pathway for membrane translocation of RasGRP3 as the main GEF activity for Ras. As shown more recently, RasGRPs and SOS can cooperate in Ras activation, which may be particularly important to amplify Ras activation under weak stimulation conditions (58).

\section{Grb2 can integrate inhibitory coreceptor signals into the BCR machinery}

The SH2 domain-containing 5'-inositol phosphatase (SHIP) $(59,60)$ complexed with phosphorylated SHC was among the first in vivo ligands for Grb2 to be described in B cells $(4,39$, 61-64). The interaction was mapped to the C-terminal SH3 domain of Grb2, which associates with one or more of the proline-rich consensus binding motifs present in the C-terminus of various SHIP isoforms. Importantly, co-clustering of the $\mathrm{BCR}$ with the negative regulatory $\mathrm{F}_{\mathrm{C}}$ receptor for IgG (Fc $\gamma$ RIIb) was required for both maximal tyrosine phosphorylation of SHIP and its association with SHC (65).

SHIP is the major effector of Fc $\gamma$ RIIb-mediated signal inhibition that limits B-cell activation (66-69). Dephosphorylation of the $5^{\prime}$-position in phosphatidylinositides by activated SHIP targets membrane recruitment of signaling proteins with a pleckstrin homology $(\mathrm{PH})$ domain (70) that posses a binding specificity for such phospholipid moieties. The most prominent example is inhibition of membrane translocation of the Tec family kinase Btk $(71,72)$. As a consequence, BCR-induced $\mathrm{Ca}^{2+}$ mobilization and B-cell function are dramatically reduced by simultaneous co-engagement of Fc $\gamma$ RIIb (73-77). However, even in the absence of Fc $\gamma$ RIIb interference, the BCR-induced $\mathrm{Ca}^{2+}$ response of SHIP-deficient B-cell mutants is greatly elevated compared with that of their wildtype counterparts (77). This observation suggests a BCR-autonomous linkage to SHIP as part of a feedback inhibition circuit. Moreover, other $\mathrm{Ca}^{2+}$-mobilizing enzymes whose BCR-induced activation is sensitive to inhibition of $\mathrm{PH}$ domain-mediated membrane recruitment are potential SHIP targets. For example, SHIP has been reported to inhibit the PKB/Akt-triggered B-cell survival pathway (78), which is downstream of phosphatidylinositol 3-kinase (PI3K) and requires several $\mathrm{PH}$ domain/phospholipid interactions for activation $(79,80)$.

Although SHIP-mediated signal inhibition of B-cell activation is now well established, the exact role of the SHIP ligand Grb2 for this process is not entirely clear. Binding of SHIP to the phosphorylated immunoreceptor tyrosine-based inhibi- 
tion motif (ITIM) (81) in the Fc $\gamma$ RIIb cytoplasmic domain can occur directly via the SH2 domain of SHIP (66-69). However, a second tyrosine-based phosphorylation site in Fc $\gamma$ RIIb is of the YXN type, and binding to the SH2 domain of either Grb2 or Grap was necessary for robust co-immunoprecipitation of SHIP isoforms with Fc $\gamma$ RIIb (82). This finding suggests that stable anchoring of SHIP at the Fc $\gamma$ RIIb tail requires the formation of a ternary complex in which SHIP binds directly to the phospho-ITIM and indirectly to the phospho-YXN motif via its linkage to the SH3 domain of either Grb2 or Grap. It is assumed that the subcellular relocalization process of SHIP rather than the regulation of its enzymatic activity is the major determinant for SHIP action on its substrate (83). Hence, Grb2 and Grap act as an amplifier of SHIP-mediated signal inhibition downstream of Fc $\gamma$ RIIb.

Two other prominent ligand-regulated coreceptors, CD22 and CD72, downmodulate BCR-induced $\mathrm{Ca}^{2+}$ flux by virtue of their cytoplasmic ITIM sequences. Upon phosphorylation, CD22 and CD72 directly recruit the SH2 domain-containing protein tyrosine phosphatase SHP-1, resulting in dephosphorylation of proximal BCR effector proteins including Ig- $\alpha / \beta$ and SLP-65 $(84,85)$. In addition to the SHP-1 effector and in analogy to Fc $\gamma$ RIIb, Grb2 is recruited via its $\mathrm{SH} 2$ domain to phospho-YXN motifs present in both $\operatorname{CD} 22(86,87)$ and CD72 $(88,89)$. Moreover, the SHP-2 isoform and Grb2 can directly bind each other via the $\mathrm{SH} 2$ and C-terminal SH3 domains of Grb2, although these interactions have not been demonstrated to occur in B cells $(90,91)$.

In summary, negative regulatory phosphatases with specificity for either membrane phospholipids or tyrosine-phosphorylated proteins are powerful tools to inhibit BCR activation at an early step. The implementation of Grb2 into that process allows modulation of the binding avidity between the coreceptor and the phosphatase and connection of the phosphatases to those coreceptors that lack an appropriate ITIM sequence to directly recruit the enzyme via the $\mathrm{SH} 2$ domain. The latter option greatly expands the number of modulatory coreceptor species that are able to use SHIP, thereby increasing the possibilities to fine tune B-cell responses.

\section{Subcellular navigation of Grb2 by transmembrane and membrane-associated adapters controls positive versus negative signal output}

The ability of Grb2 to act as a negative regulatory element during BCR-induced $\mathrm{Ca}^{2+}$ flux was directly demonstrated by the analysis of Grb2-deficient DT40 B-cell mutants (92), which had been generated by gene targeting (93). Lack of
Grb2 expression enhances the release of $\mathrm{Ca}^{2+}$ from intracellular stores of the endoplasmic reticulum as well as the subsequent entry of extracellular $\mathrm{Ca}^{2+}$ through plasma membrane channels. The sustained biphasic $\mathrm{Ca}^{2+}$ profile of the parental DT40 cells was restored by re-introduction of wildtype Grb2 but not by Grb2 mutants in which either the SH2 or C-terminal SH3 domain had been inactivated by point mutations. The partner molecule of Grb2 in this inhibitory cascade is the hematopoietic adapter protein downstream of kinase-3 (Dok-3) $(94,95)$, which upon phosphorylation by Lyn provides specific pYXN docking sites for the Grb2 SH2 domain (96). Dok-3 contains an N-terminal PH domain for lipid raft localization followed by a PTB domain that binds phosphorylated SHIP. Mutational analysis and reconstitution experiments in Dok-3-negative DT40 B cells revealed that loss of membrane association abrogates Dok-3 phosphorylation, Grb2 recruitment, and concomitant inhibition of $\mathrm{Ca}^{2+}$ flux. The cascade did surprisingly not require SHIP (96). When bound to Dok-3 in lipid rafts via the SH2 domain, Grb2 suppresses Btk-mediated PLC- $\gamma 2$ activation either by allosteric inhibition of Btk activity or by preventing incorporation of Btk into the SLP-65-assembled $\mathrm{Ca}^{2}{ }^{+}$initiation complex. Ablation of Dok-3 expression in mice did not affect B-cell development but resulted in hyperproliferation of the $\mathrm{B}$ cells and in enhanced activation of several BCR signaling cascades including $\mathrm{Ca}^{2+}$ mobilization (97).

Grb2 is produced in almost similar amounts during all stages of B-cell development. Yet, the shape of the $\mathrm{Ca}^{2+}$ mobilization profiles markedly differs between various B-cell subpopulations $(50,98)$. DT40 B cells represent an immature stage of development in which $\mathrm{B}$ cells exhibit a more moderate $\mathrm{Ca}^{2+}$ response. It is thus likely that mechanisms to subvert inhibitory Grb2 signaling in mature immunocompetent B cells exist. One identified antagonist of the Dok-3/Grb2 module is the non-T-cell activation linker (NTAL) (92). NTAL was identified based on its structural homology to linker for activation of T cells (LAT) and is therefore also called LAT2 (99). LAT and NTAL belong to the family of transmembrane adapter proteins characterized by a short extracellular peptide stretch, a transmembrane helix, and an intracellular segment accommodating a number of protein-protein interaction sites (99). Many of the family members, including LAT and NTAL, carry post-translational fatty acid modifications at conserved cysteine residues in the juxtamembrane part and are permanent residents of lipid rafts. Linker of activated X cells (LAX) (97), which is also present in B cells, resides outside of the lipid rafts. A common and functionally relevant feature of transmembrane adapters is their ability to associate with Grb2 
via one or more pYXN sites. Recruitment of Grb2 to phosphorylated NTAL counteracts its capacity to attenuate BCR-induced $\mathrm{Ca}^{2+}$ fluxes (92). The mobilization profile of NTAL-positive B cells is almost identical to that of Grb2-negative cells. By introducing NTAL expression, the moderate $\mathrm{Ca}^{2+}$ flux of NTAL-negative DT40 B cells was converted into a robust response reminiscent to that of mature $B$ cells. Expression analysis in primary mouse B cells and B-cell lines showed that NTAL expression increases as the cells mature.

The phosphorylated adapter proteins Dok-3 and NTAL provide two functionally inverse membrane anchors for cytosolic Grb2 in B cells. The available data suggest that NTAL sequesters Grb2 away from Dok-3, a liaison, which drags Grb2 into a microenvironment that allows for inhibition of the $\mathrm{Ca}^{2+}$ initiation complex. Hence, NTAL is not a bona fide positive B-cell regulator but acts more like a mute button for Dok-3 action. Functionally redundant molecules of NTAL are likely to exist, as indicated by the mild immunological phenotype of NTALnegative mouse mutants (100). NTAL has been shown in other cell types, notably $\mathrm{T}$ and mast cells, to function as a negative regulator by counteracting LAT (99). LAT is the critical membrane-anchoring platform for the $\mathrm{Ca}^{2}+$ initiation complex in T cells and therefore associates with Gads and PLC- $\gamma 1$. NTAL lacks the PLC- $\gamma 1$-binding site but efficiently binds Gads. Thus, when simultaneously expressed, NTAL competes with LAT for Gads binding and reduces the number of available Gads molecules for the $\mathrm{Ca}^{2+}$ initiation complex. The principle mechanism is basically the same as for Dok-3 regulation in B cells, i.e., phosphorylated NTAL provides an alternative membrane destination for a Grb2 family member. Whether the net result of this alternative binding is stimulatory or inhibitory for the cell is determined by the function of the Grb2 binder that is counteracted by NTAL. It also is a main and more general lesson learned from these studies that signaling controlled by the subcellular relocalization of Grb2 not just involves transportation of the protein from the cytosol to the plasma membrane. Rather, precise targeting to individual lipid raft residents is a key parameter of signal output. This suggests that even within the lipid rafts, the lateral mobility of proteins is limited, which prevents their random interaction and unwanted crosstalk between signal pathways.

\section{Amplification of B-cell activation by incorporation of Grb2 into the BCR and the CDI9 coreceptor}

No direct association between the BCR and Grb2 had been reported until recently. Consistent with a lack of a BCR/Grb2 interaction is the absence of consensus phosphorylation motifs of the YXN type and appropriate proline-rich recognition motifs that might provide Grb2 docking sites in Ig- $\alpha$ and Ig- $\beta$. However, the cytoplasmic segments of membranebound $\operatorname{IgG}$ and $\operatorname{IgE}$ (mIgG and mIgE, respectively) contain an evolutionarily conserved tyrosine residue followed by an asparagine in the +2 position. In $\mathrm{mIgG}$ isoforms, the $\mathrm{Y}+1$ position carries a positively charged arginine (except for murine $\gamma 1$, which harbors a lysine), and a methionine is present in the $\mathrm{Y}+3$ position. In the case of the mIgE cytoplasmic segments, the $Y+1$ and $Y+3$ positions vary between different species. Our group showed that the conserved tyrosine residue, now named as immunoglobulin tail tyrosine (ITT), underwent inducible phosphorylation and Grb2 recruitment following stimulation of the IgG- and IgE-BCR (101). ITT/Grb2 complex formation boosted $\mathrm{Ca}^{2+}$ mobilization and proliferative responses in various B-cell lines and primary B cells of the mouse. Mutant BCRs in which the ITT was inactivated by a phenylalanine substitution showed almost identical responses to tailless mIg variants or to the IgM-BCR. Hence, the ITT is a key element that distinguishes IgG/E-BCR signaling on class-switched memory $B$ cells from that of the IgM-BCR expressed on newly generated cells. The data explain the observed burst-enhancing role of the IgG tail segment in genetically engineered mouse models (102-105).

Several mechanisms for how an ITT/Grb2 complex promotes B-cell activation can be considered.As the C-terminal SH3 domain of Grb2 constitutively interacts with SLP-65 (106), Grb2 may bring additional $\mathrm{Ca}^{2+}$ initiation complexes to the plasma membrane and directly to the activated BCR. Moreover, ITT-bound Grb2 is not available for signal inhibition via Dok-3 (see above) $(92,96)$. It is also likely that the presence of Grb2 stabilizes the 'open' conformation of the activated $\operatorname{Ig} \alpha / \operatorname{Ig} \beta$ heterodimer (107). Despite the fact that the IT'T in $\mathrm{mIgG}$ matches the consensus pYXXM docking site for the p85 regulatory subunit of PI3K, no evidence was obtained that PI3K activity contributes to ITT signaling (101). A likely explanation for the absence of PI3K signaling is that the positively charged arginine/lysine residue in the $\mathrm{Y}+1$ position of the ITT is not tolerated by SH2 domain of p 85 but only by that of Grb2 (see above) (6). Collectively, the phosphorylated ITT and its association with Grb2 constitute a highly selective signaling module that provides BCR-intrinsic costimulation to mIgG and mIgE class-switched memory B cells and may render them less dependent on costimulation by helper $\mathrm{T}$ cells.

A positive regulatory role of Grb2 in BCR signaling is also suggested by the high affinity binding of the Grb2 $\mathrm{SH} 2$ domain to phospho-YXN sites in CD19 (108, 109), which in conjunction with the complement receptor 2 (CD21) and CD81 (TAPA) forms a prominent coreceptor complex for BCR 
signal amplification (110). Consistent with the abnormal B-cell development and function in genetically engineered CD19 mouse mutants $(111,112)$, autoimmune diseases and primary antibody deficiency syndromes in human patients are caused by CD19 hyper- or hypofunction, respectively $(113,114)$.

The potent B-cell activation function of CD19 is accomplished by several SH2 domain-containing effector molecules that bind to CD19 in stimulation-dependent and in a constitutive manner (110). Formation of the signalosome requires Lyn, which phosphorylates CD19. Amplification of $\mathrm{Ca}^{2+}$ mobilization is achieved by direct PLC- $\gamma 2$ recruitment and possibly also by binding of Vav isoforms, which provide GEF activity for small $\mathrm{G}$ proteins of the Rho/Rac family and have been implicated in $\mathrm{Ca}^{2+}$ flux regulation by the BCR. Vav isoforms can partially substitute for each other, but in the absence of all three Vav isoforms, BCR-evoked $\mathrm{Ca}^{2}{ }^{+}$flux is completely abrogated (115). It has been demonstrated more recently that CD19, PLC- $\gamma 2$, and Vav cooperate during formation of the immunological B-cell synapse and propagation of B-cell spreading $(116,117)$, most likely by reorganizing the actin cytoskeleton through activation of Rho/Rac-dependent pathways (118). CD19-associated Vav can also contribute to activation of PI3K and the Akt/PKB survival pathway (119). One key event for PI3K activation in B cells is CD19-mediated membrane translocation of the regulatory p85 subunit. A second event, which plays a synergistic and non-redundant role in PI3K activation, is association of p85 to the tyrosine-phosphorylated B-cell adapter for PI3K (BCAP) (120, 121). No PI3K activation is observed in mouse $\mathrm{B}$ cells that lack both CD19 and BCAP (122). How the BCAP/p85 complex is recruited to the plasma membrane and how exactly it feeds into pathway activation is unclear. Possibly phosphorylation of the YXN consensus motifs in BCAP initiates association with Grb2 and helps to target BCAP to its proper membrane destination. Grb2 may more directly contribute to CD19-mediated B-cell costimulation than it promotes B-cell inhibition via phosphatases (see above), i.e. by increasing the avidity of complex formation between CD19 and its effector through a second linkage for this effector at the coreceptor. A single Vav molecule may be anchored directly to CD19 through its own SH2 domain and indirectly through its SH3 domain, which forms an unusual dimer with the C-terminal SH3 domains of Grb2 (123-125) bound to CD19 via a pYXN motif. This multi-layered tethering mechanism boosts $\mathrm{Ca}^{2}{ }^{+}$mobilization and/or formation of membrane microclusters. Consistent with this view, Vav localization in lipid rafts has been demonstrated to be controlled by Grb2 and SLP-65 (126), which itself is bound by the SH2 and SH3 domains of Grb2 $(48,49,106)$. It can of course not be excluded that CD19-bound Grb2 recruits additional yet to be identified effector proteins to CD19. Clearly the discussed possibilities of how Grb2 supports CD19-mediated B-cell activation are not mutually exclusive.

\section{A proteomic approach to elucidate the Grb2 interactome in activated $B$ cells}

In addition to the Grb2 interaction partners described above, other B-cell ligands have been detected by yeast-two-hybrid screenings or pull-down experiments with bacterially expressed fusion proteins. A plethora of Grb2 ligands has been described and functionally characterized in non-B-cell types including $\mathrm{T}$ cells. To obtain a comprehensive list of B-cell proteins that bind Grb2 in vivo, we employed stable isotope labeling by amino acids in cell culture (SILAC) in combination with high-end mass spectrometry analysis of purified protein complexes (127). This combination has been shown to be a powerful technique, not only for the quantification of proteins in complex samples (127) but also for the specific identification of protein interactions (128). The sensitivity and accuracy of this approach compares to that of co-immunoprecipitation experiments followed by Western blot analysis.

Murine Bal17.TR B cells, which lack endogenous Grb2 expression (63), were reconstituted with either wildtype Grb2 or with a Grb2 variant that harbors an C-terminal OneStrep-Tag (IBA BioTagnologies). The former transfectants were metabolically labeled in SILAC medium containing 'light' forms of the two amino acids lysine and arginine $\left(\left[{ }^{12} \mathrm{C}_{6},{ }^{14} \mathrm{~N}_{2}\right]\right.$-Lys, $\left[{ }^{12} \mathrm{C}_{6},{ }^{14} \mathrm{~N}_{4}\right]$-Arg). The latter transfectants, expressing tagged Grb2, were cultured with 'heavy' forms of lysine and arginine $\left(\left[{ }^{2} \mathrm{D}_{4},{ }^{12} \mathrm{C}_{6},{ }^{14} \mathrm{~N}_{2}\right]\right.$-Lys, $\left[{ }^{13} \mathrm{C}_{6},{ }^{14} \mathrm{~N}_{4}\right]$-Arg $)$. To control for side effects of the labeling procedure, we also performed experiments in which cells were cultured in the converse manner. The differentially labeled cells were stimulated through their IgM-BCR for $5 \mathrm{~min}$. Proteins were purified from the lysates with a Strep-Tactin column (IBA BioTagnologies) (129). The obtained protein fractions were pooled at a $1: 1$ ratio, separated by one-dimensional gel electrophoresis, and in-gel digested with endoproteinase trypsin. Peptide fragments were extracted and analyzed by liquid-chromatography-coupled tandem mass spectrometry (MS/MS) on an Orbitrap XL-mass spectrometer. The data were processed by the MaxQuant software $(130,131)$ to identify the corresponding proteins and to obtain accurate quantitative ratios for both samples. The quantification is made possible because the tryptic peptides derived from the differentially labeled cells can be distinguished in the mass spectrometer, owing to their specific mass shift that results from the distinct incorpo- 
ration of heavy or light amino acids. The signal intensities of the peaks in the heavy versus light MS spectra (H/L ratio) correspond to the relative abundance of the peptides in each sample. This approach allows for discrimination between those proteins that non-specifically adhere to the matrix and those that are specifically affinity-purified and hence represent in vivo ligands for Grb2. The former can be detected by their appearance in both preparations a ratio of approximately $1: 1$. The peptide peak intensities of the affinity-purified Grb2 ligands are much higher in the sample preparation from cells expressing tagged Grb2 than in the negative control sample obtained from cells expressing untagged Grb2. As an example, Fig. 1 shows an MS spectrum corresponding to the peptide EAISLVC $_{\text {carb }}$ EAVPGAK derived from the Grb2 ligand SHC. This particular peptide was almost exclusively found in the sample preparation from Bal17.TR cells expressing tagged Grb2, which were in this case labeled with heavy amino acids. The corresponding light version of this SHC peptide was almost undetectable. Table 1 shows the number of peptides identified for each ligand, the posterior error probability (PEP) of the identified proteins, and their relative abundance ratio for the two Bal17.TR transfectant lines cultured in SILAC medium in the combination light plus heavy and vice versa. The PEP together with the abundance ratio allows to unambiguously assign the identified protein as a Grb2 ligand in an unbiased manner. Our analysis is summarized in Table 1, and a comprehensive overview of the Grb2 interactome in B cells is depicted in Fig. 2.

The quantitative proteomic approach showed that the negative regulators SHIP1 and Dok-3 are the most frequently detected interacting proteins of Grb2 in Bal17.TR B cells. Protein tyrosine phosphatases are also prominently represented. In addition to SHP-1 and SHP-2, we detected the transmembrane phosphatase PTPR $\alpha$ and the cytosolic phosphatase PTPPEST as novel B-cell ligands for Grb2. PTPR $\alpha$ comprises a short extracellular domain of 123 amino acids and two cytoplasmic phosphatase domains. Expression of PTPR $\alpha$ has not yet been described in B cells, but its interaction with the SH2 and C-terminal SH3 domain of Grb2 has been shown to occur in fibroblasts $(132,133)$. A wealth of evidence exists for the importance of PEST family phosphatases in immune cell activation and autoimmune inflammatory disorders (134).

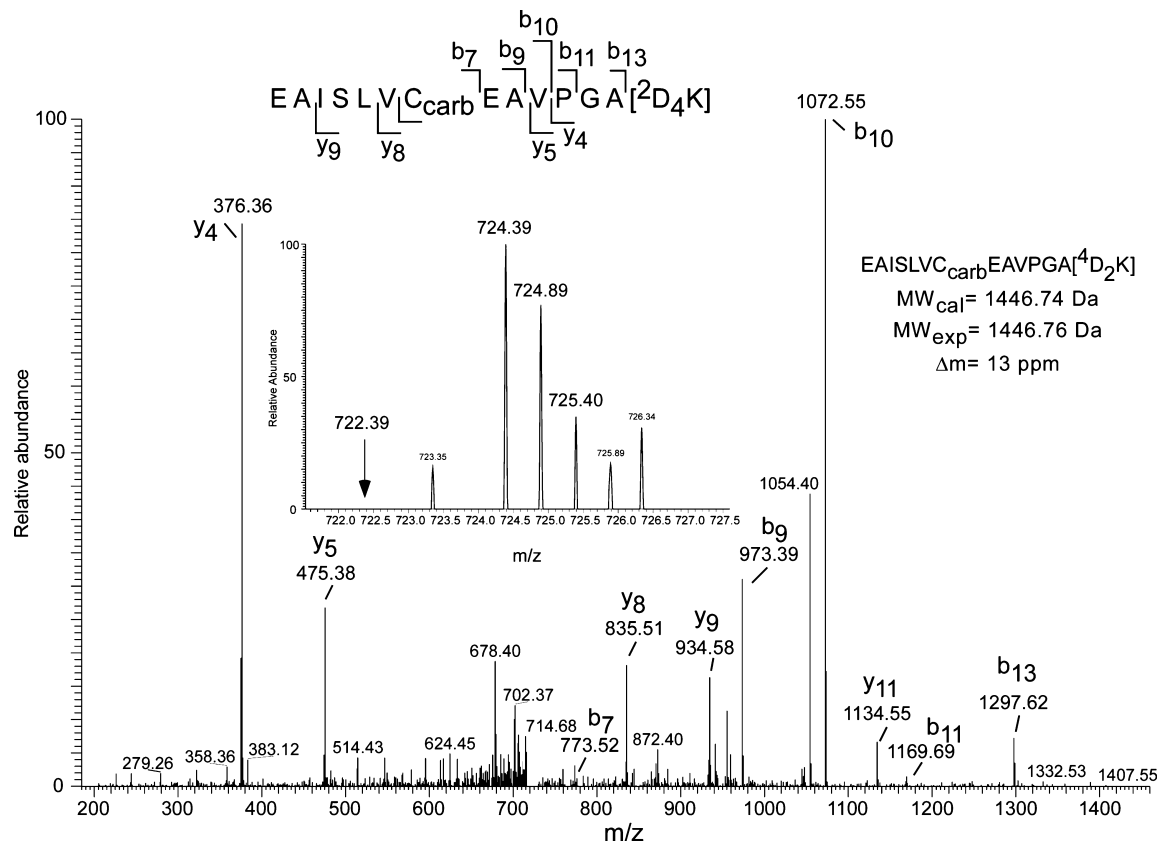

Fig. 1. Example of a mass spectrometric (MS) analysis for the identification of Grb2 ligands. The depicted MS and MS/MS spectra are derived from tryptic peptides obtained from the mixture of proteins purified with tagged Grb2 and untagged Grb2 (negative control). The presence of the 'heavy' lysine (resulting in a mass shift of +4 atomic mass units) shows that the peptide is derived from cells which were SILAC-labeled with heavy amino acids and expressed (in this particular experiment) tagged Grb2. The peptide has a mass of 1446.76, is doubly charged, and has its mono-isotopic peak at a mass-to-charge ratio $(\mathrm{m} / \mathrm{z})$ of 724.39 in the full scan (central diagram). The $\mathrm{m} / \mathrm{z}$ value of the corresponding peptide, which accommodates a 'light' lysine (+0) and is therefore derived from the sample preparation of cells expressing the untagged Grb2 version, is around 724.39. As this light peptide is below the detection limit, the protein that gave rise to the heavy peptide is unambiguously identified as being specifically affinitypurified with tagged Grb2and thus a Grb2 ligand. To deduce the amino acid sequence, the peptide was fragmented by collision-induced decay (CID), and fragments were recorded to give the MS/MS scan (below the full scan). The resulting fragment ions were searched through databases to eventually identify the peptide and assign it to SHC, in this case. 


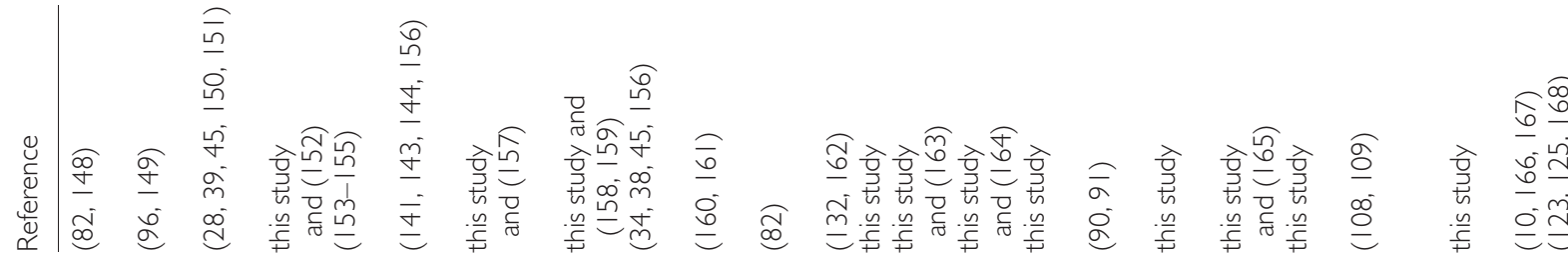

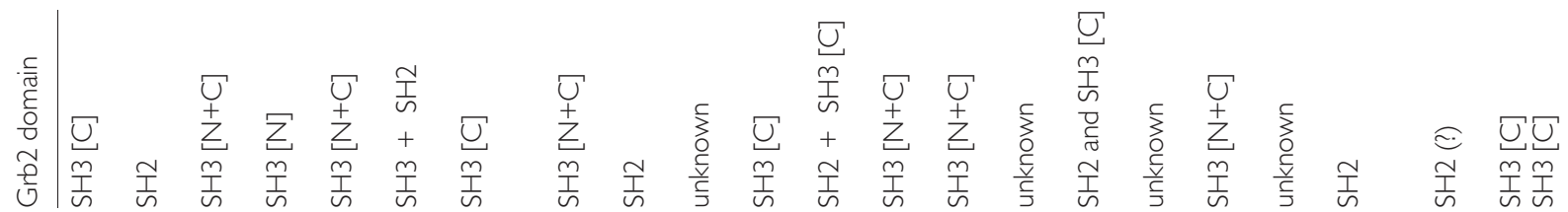

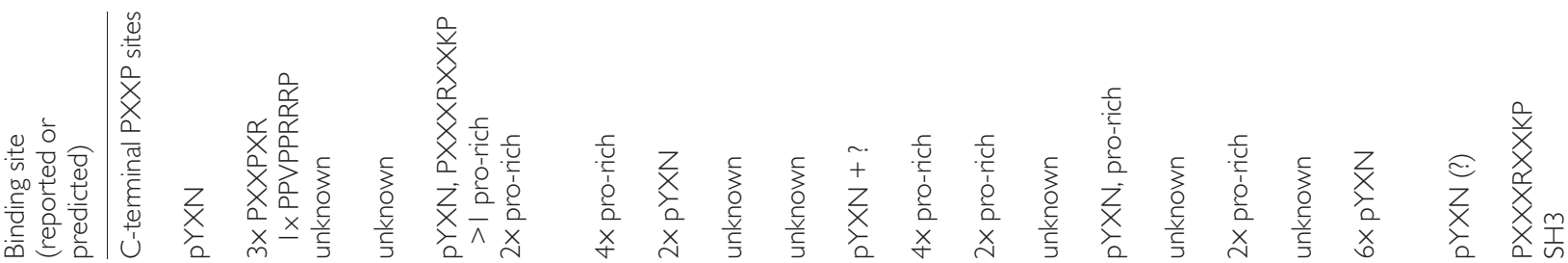

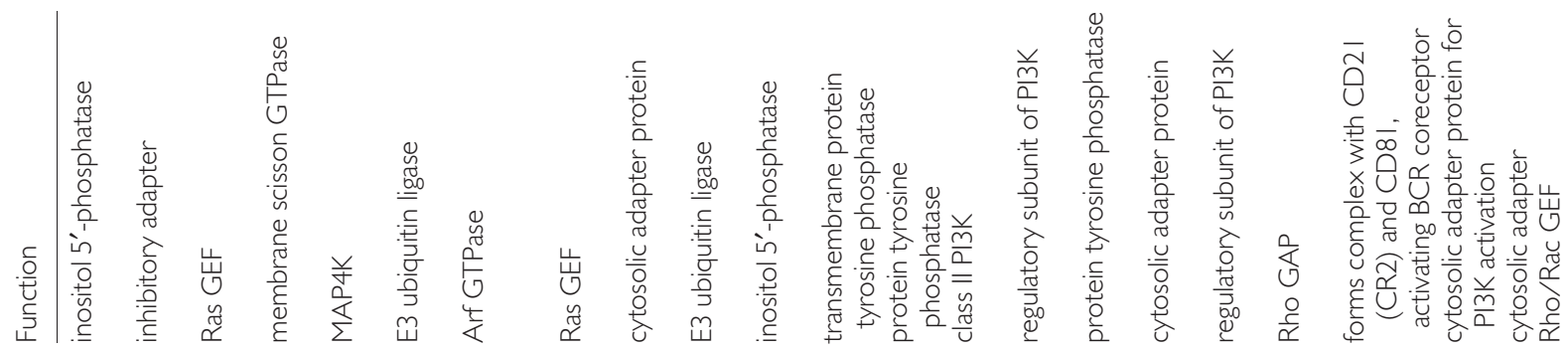

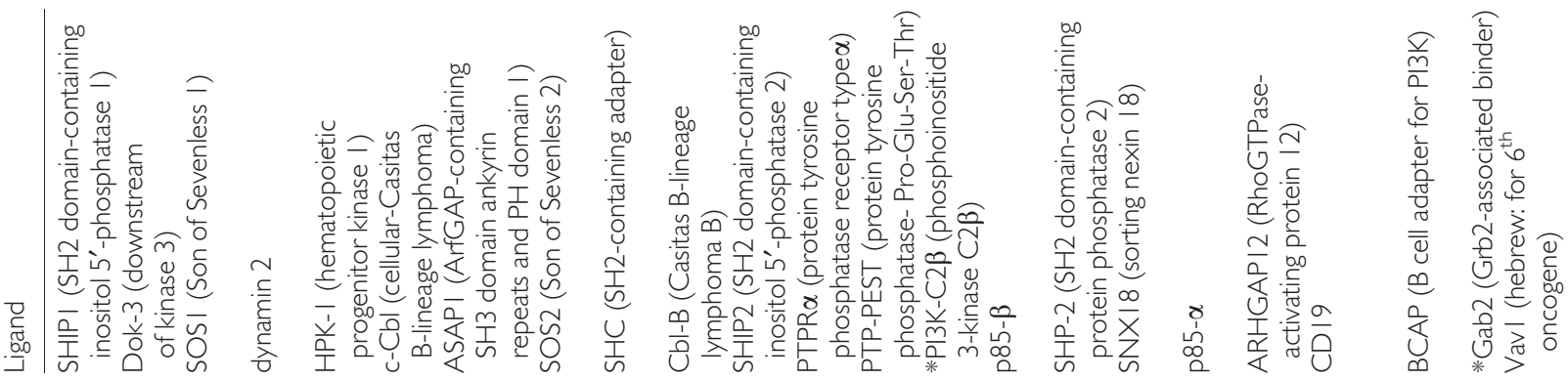

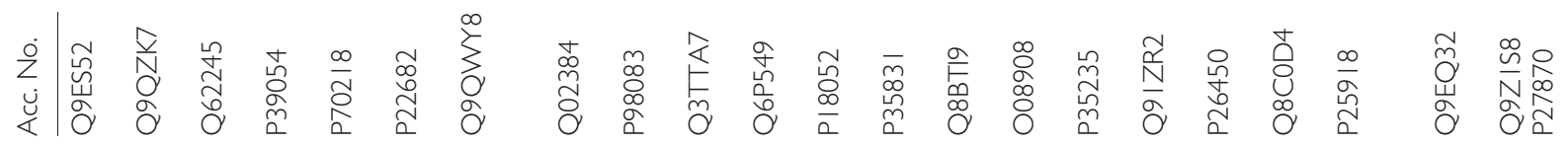

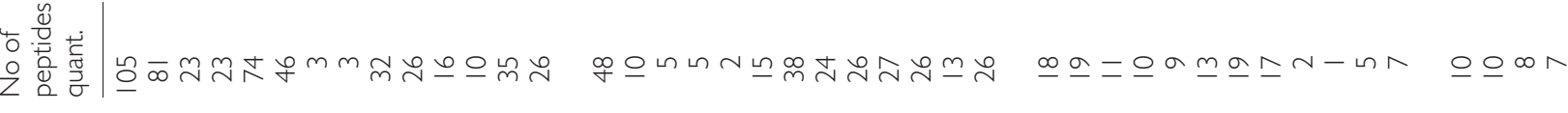

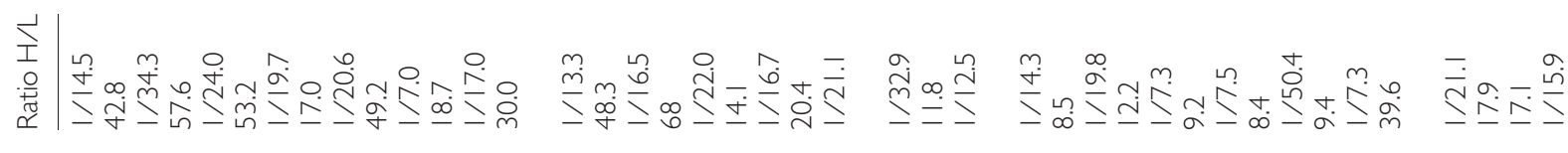

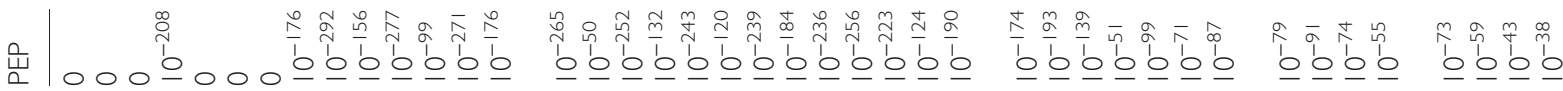




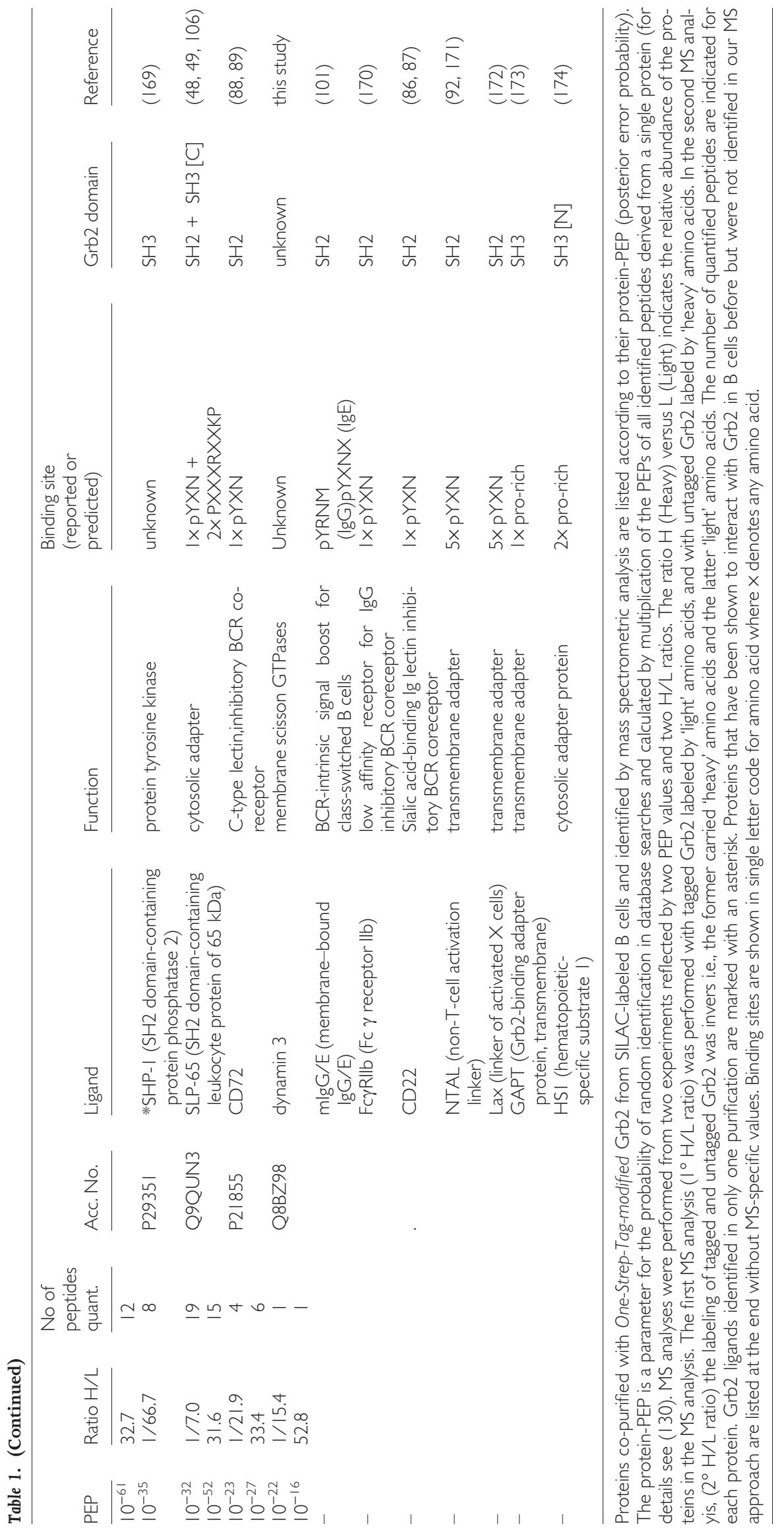




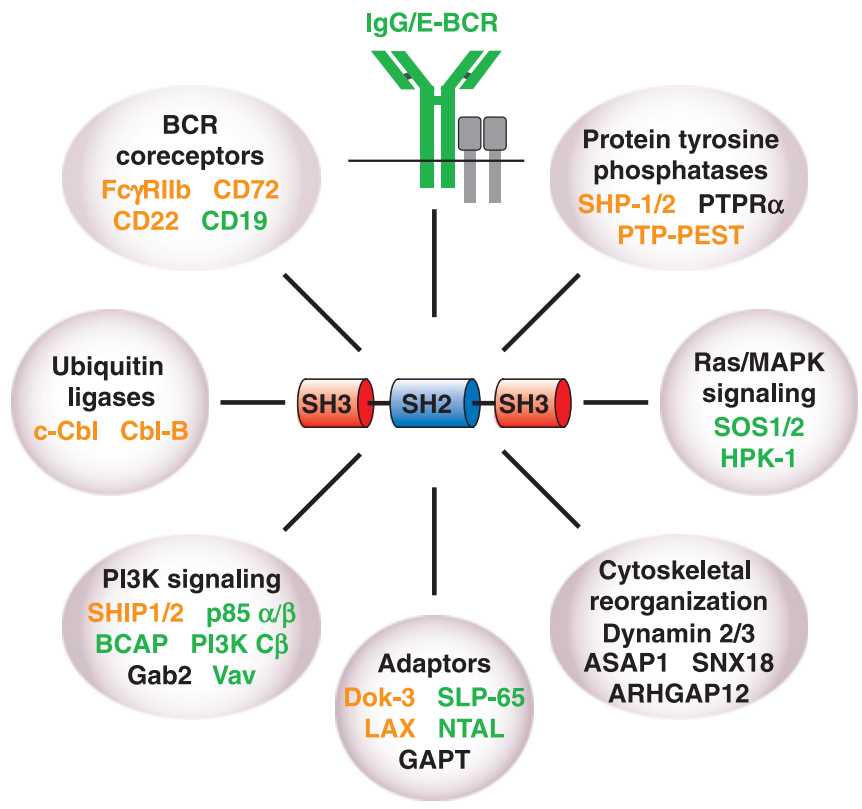

Fig. 2. The interactome of Grb2 in B cells. The SH2 and SH3 domains of Grb2 (center) interact with positive (green) and negative (orange) signal regulators of different pathways.

The proto-oncoprotein and E3 ubiquitin ligase $\mathrm{Cbl}$ (for Casitas B-lineage lymphoma) together with Cbl-B are two other well-known inhibitors of B-cell activation $(135,136)$, and both were detected frequently as Grb2 binders in our SILAC/MS approach. Cbl proteins control the induction of B-cell tolerance by adjusting the BCR signaling threshold through ubiquitinylation of Syk and its concomitant targeting to proteolytic degradation (137-139). Furthermore, Cbl activity regulates proteolysis of the antigen-ligated $\mathrm{BCR}$ complex following its internalization (140). Cbl and Grb2 have been co-immunoprecipitated from B-cell lysates (141), but the molecular details of this interaction have been worked out in other cell types and for Gads and GrpL (142-144).

Under the stimulation conditions utilized, the negative regulatory coreceptors Fc $\gamma$ RIIb and CD22 were not detected in our proteomic screen. Lack of the former is explained by the absence of co-crosslinking Fc $\gamma$ RIIb with the BCR, which is required for efficient Grb2 recruitment (see above). Expression of CD22 in Bal17.TR B cells needs to be confirmed. Phosphorylated mIgG and mIgE were missed, because Bal17.TR cells express an IgM-BCR. The Grb2 binder NTAL and LAX are lipid raft residents, which, dependent on the detergent conditions, are sometimes difficult to solubilize and hence may be lost during the purification procedure. The Grb2 ligands that were absent in our analysis are listed at the end of Table 1 without a PEP value.

Among the novel and frequently detected B-cell ligands of Grb2 are cytoskeleton components implicated in actin reorga- nization and vesicle trafficking (Table 1). The association of Grb2 with SOS1 has been extensively discussed above, and the prominent presence of SOS1, SOS2, and the hematopoietic progenitor kinase-1 (HPK-1) in our analysis may reflect the involvement of these complexes in activation of the Ras/ MAPK pathway by other receptors than the BCR. Elucidation of the Grb2 interactome in Bal17.TR B cells confirmed a prominent role of Grb2 in PI3K regulation. Grb2 associated with the enzyme's components themselves, the regulatory subunits p85 $\alpha$ and $\beta$ and the catalytic isoform $C \beta$, as well as with the two key activators CD19 and BCAP, which cooperate for full PI3K activation in B cells. Almost certainly Grb2 is directly or indirectly involved in the primary step of PI3K activation, i.e., in membrane translocation of the p85 subunits. However and as described above, the most frequently detected Grb2 ligand is SHIP, which is a main antagonist of PI3K. This apparent discrepancy is not easily explained at a mechanistic level. It however suggests the existence of distinct cellular Grb2 pools that navigate along discrete pathways without crosstalk. This conclusion again emphasizes the importance of precise subcellular localization for signaling homeostasis.

\section{Concluding remarks}

Despite the remarkably simple architecture, Grb2 is one of the most versatile proteins in signal transduction. Currently, 194 interaction partners of Grb2 are listed in the Human Protein 
Reference Database (145), and 515 Grb2 ligands are described in the IntAct database (146). It is thus easy to comprehend the embryonic lethality upon global loss of Grb2 expression in mice (147). B-cell-specific ablation of Grb2 expression in the mouse has not yet been described, but the multiple roles of Grb2 in positive and negative regulatory cascades suggest indispensable contributions of Grb2 for proper signal integra- tion to induce and maintain B-cell tolerance. Some Grb2 functions however may be redundant and replaced in the case of Grb2 deficiency by other Grb2 family members such as Gads. Deciphering the Grb2 network at a molecular level is a difficult task but will be facilitated by novel proteomic techniques to unravel protein-protein interactions in vivo.

\section{References}

1. Lowenstein EJ, et al. The Sh2 and Sh3 domain containing protein Grb2 links receptor tyrosine kinases to Ras signaling. Cell 1992;70:431-442.

2. Sadowski I, Stone JC, Pawson T. A noncatalytic domain conserved among cytoplasmic protein-tyrosine kinases modifies the kinase function and transforming activity of Fujinami sarcoma virus P130gag-fps. Mol Cell Biol 1986;6:4396-4408.

3. Matuoka K, Shibata M, Yamakawa A, Takenawa T. Cloning of ASH, a ubiquitous protein composed of one Src homology region (SH) 2 and two $\mathrm{SH} 3$ domains, from human and rat cDNA libraries. Proc Natl Acad Sci USA 1992;89:9015-9019.

4. Mayer BJ, Gupta R. Functions of SH2 and SH3 domains. Curr Top Microbiol Immunol 1998;228:1-22.

5. Songyang Z, et al. Specific motifs recognized by the SH2 domains of Csk, 3BP2, fps/fes, GRB-2, HCP, SHC, Syk, and Vav. Mol Cell Biol 1994;14:2777-2785.

6. Kessels HW, Ward AC, Schumacher TN. Specificity and affinity motifs for Grb2 SH2-ligand interactions. Proc Natl Acad Sci USA 2002;99:8524-8529.

7. Feng S, Chen JK, Yu H, Simon JA, Schreiber SL. Two binding orientations for peptides to the Src SH3 domain: development of a general model for SH3-ligand interactions. Science 1994;266:1241-1247.

8. Sparks AB, Rider JE, Hoffman NG, Fowlkes DM, Quillam LA, Kay BK. Distinct ligand preferences of Src homology 3 domains from Src, Yes, Abl, Cortactin, p53bp2, PLCgamma, Crk, and Grb2. Proc Natl Acad Sci USA 1996;93:1540-1544.

9. Lewitzky M, et al. The C-terminal SH3 domain of the adapter protein Grb2 binds with high affinity to sequences in Gab1 and SLP-7 6 which lack the SH3-typical P-x-x-P core motif. Oncogene 2001;20:10521062.

10. Harkiolaki M, et al. Distinct binding modes of two epitopes in Gab2 that interact with the SH3C domain of Grb2. Structure 2009;17:809-822.

11. Maignan S, Guilloteau JP, Fromage N, Arnoux B, Becquart J, Ducruix A. Crystal structure of the mammalian Grb2 adaptor. Science 1995;268:291-293.

12. Yuzawa $S$, et al. Solution structure of Grb2 reveals extensive flexibility necessary for target recognition. J Mol Biol 2001;306:527537.

13. Feng GS, Ouyang YB, Hu DP, Shi ZQ, Gentz $\mathrm{R}$, Ni J. Grap is a novel SH3-SH2-SH3 adaptor protein that couples tyrosine kinases to the Ras pathway. J Biol Chem 1996;271:12129-12132.

14. Liu SK, McGlade CJ. Gads is a novel SH2 and SH3 domain-containing adaptor protein that binds to tyrosine-phosphorylated Shc. Oncogene 1998;17:3073-3082.

15. Law CL, et al. GrpL, a Grb2-related adaptor protein, interacts with SLP-76 to regulate nuclear factor of activated $\mathrm{T}$ cell activation. J Exp Med 1999;189:1243-1253.

16. Bourette RP, Arnaud S, Myles GM, Blanchet JP, Rohrschneider LR, Mouchiroud G. Mona, a novel hematopoietic-specific adaptor interacting with the macrophage colony-stimulating factor receptor, is implicated in monocyte/macrophage development. EMBO J 1998;17:7273-7281.

17. Ellis JH, Ashman C, Burden MN, Kilpatrick KE, Morse MA, Hamblin PA. GRID: a novel Grb-2-related adapter protein that interacts with the activated $\mathrm{T}$ cell costimulatory receptor CD28. J Immunol 2000;164: 5805-5814.

18. Asada H, et al. Grf40, A novel Grb2 family member, is involved in $\mathrm{T}$ cell signaling through interaction with SLP-76 and LAT. J Exp Med 1999;189:1383-1390.

19. Qiu M, et al. Molecular cloning and expression of human grap-2, a novel leukocytespecific SH2- and SH3-containing adaptorlike protein that binds to gab-1. Biochem Biophys Res Commun 1998;253:443-447.

20. Kayne PS, Sternberg PW. Ras pathways in Caenorhabditis elegans. Curr Opin Genet Dev 1995;5:38-43.

21. Simon MA. Signal transduction during the development of the Drosophila R7 photoreceptor. Dev Biol 1994; 166:431-442.

22. Hafen E, Basler K, Edstroem JE, Rubin GM. Sevenless, a cell-specific homeotic gene of Drosophila, encodes a putative transmem- brane receptor with a tyrosine kinase domain. Science 1987;236:55-63.

23. Olivier JP, et al. A Drosophila SH2-SH3 adaptor protein implicated in coupling the sevenless tyrosine kinase to an activator of Ras guanine nucleotide exchange, Sos. Cell 1993;73:179-191.

24. Simon MA, Dodson GS, Rubin GM. An SH3$\mathrm{SH} 2-\mathrm{SH} 3$ protein is required for $\mathrm{p} 21$ Ras 1 activation and binds to sevenless and Sos proteins in vitro. Cell 1993;73:169-177.

25. Buday L, Downward J. Epidermal growth factor regulates $\mathrm{p} 21$ ras through the formation of a complex of receptor, Grb2 adapter protein, and Sos nucleotide exchange factor. Cell 1993;73:611-620.

26. Egan SE, Giddings BW, Brooks MW, Buday L, Sizeland AM, Weinberg RA. Association of Sos Ras exchange protein with Grb2 is implicated in tyrosine kinase signal transduction and transformation. Nature 1993; 363:45-51.

27. Gale NW, Kaplan S, Lowenstein EJ, Schlessinger J, Bar-Sagi D. Grb2 mediates the EGFdependent activation of guanine nucleotide exchange on Ras. Nature 1993;363:88-92.

28. Li N, et al. Guanine-nucleotide-releasing factor hSos 1 binds to Grb2 and links receptor tyrosine kinases to Ras signalling. Nature 1993;363:85-88.

29. Rozakis-Adcock M, Fernley R, Wade J, Pawson T, Bowtell D. The SH2 and SH3 domains of mammalian Grb2 couple the EGF receptor to the Ras activator mSos 1 . Nature 1993;363:83-85.

30. Skolnik EY, et al. The SH2/SH3 domaincontaining protein GRB2 interacts with tyrosine-phosphorylated IRS1 and Shc: implications for insulin control of ras signalling. EMBO J 1993;12:1929-1936.

31. Buday L, Downward J. Many faces of Ras activation. Biochim Biophys Acta 2008;1786:178-187.

32. Stern MJ, et al. The human GRB2 and Drosophila Drk genes can functionally replace the Caenorhabditis elegans cell signaling gene sem-5. Mol Biol Cell 1993;4:11751188.

33. Pelicci G, et al. A novel transforming protein (SHC) with an $\mathrm{SH} 2$ domain is 
implicated in mitogenic signal transduction. Cell 1992;70:93-104.

34. Rozakis-Adcock M, et al. Association of the Shc and Grb2/Sem5 SH2-containing proteins is implicated in activation of the Ras pathway by tyrosine kinases. Nature 1992; 360:689-692.

35. Reth $\mathrm{M}$, Wienands J. Initiation and processing of signals from the B cell antigen receptor. Annu Rev Immunol 1997;15:453-479.

36. Kurosaki T, Hikida M. Tyrosine kinases and their substrates in B lymphocytes. Immunol Rev 2009;228:132-148.

37. Tordai A, Franklin RA, Patel H, Gardner AM, Johnson GL, Gelfand EW. Cross-linking of surface IgM stimulates the Ras/Raf-1/ MEK/MAPK cascade in human B lymphocytes. J Biol Chem 1994;269:7538-7543.

38. Lankester AC, van Schijndel GM, Rood PM, Verhoeven AJ, van Lier RA. B cell antigen receptor cross-linking induces tyrosine phosphorylation and membrane translocation of a multimeric Shc complex that is augmented by CD19 co-ligation. Eur J Immunol 1994;24:2818-2825.

39. Saxton TM, van Oostveen I, Bowtell D, Aebersold R, Gold MR. B cell antigen receptor cross-linking induces phosphorylation of the p21ras oncoprotein activators SHC and mSOS1 as well as assembly of complexes containing SHC, GRB-2, mSOS1, and a 145-kDa tyrosine-phosphorylated protein. J Immunol 1994;153:623-636.

40. Nagai K, Takata M, Yamamura H, Kurosaki T. Tyrosine phosphorylation of Shc is mediated through Lyn and Syk in B cell receptor signaling. J Biol Chem 1995;270:68246829.

41. Baumann G, Maier D, Freuler F, Tschopp C, Baudisch $\mathrm{K}$, Wienands J. In vitro characterization of major ligands for Src homology 2 domains derived from protein tyrosine kinases, from the adaptor protein SHC and from GTPase-activating protein in Ramos B cells. Eur J Immunol 1994;24:1799-1807.

42. D’Ambrosio D, Hippen KL, Cambier JC. Distinct mechanisms mediate SHC association with the activated and resting B cell antigen receptor. Eur J Immunol 1996;26:1960-1965.

43. Smit L, de Vries-Smits AM, Bos JL, Borst J. $B$ cell antigen receptor stimulation induces formation of a Shc-Grb2 complex containing multiple tyrosine-phosphorylated proteins. J Biol Chem 1994;269:20209-20212.

44. Smit L, van der Horst G, Borst J. Sos, Vav, and C3G participate in B cell receptorinduced signaling pathways and differentially associate with Shc-Grb2, Crk, and Crk-L adaptors. J Biol Chem 1996;271:8564-8569.

45. Harmer SL, DeFranco AL. Shc contains two Grb2 binding sites needed for efficient formation of complexes with SOS in B lymphocytes. Mol Cell Biol 1997;17:40874095.

46. Oh-hora M, Johmura S, Hashimoto A, Hikida M, Kurosaki T. Requirement for Ras guanine nucleotide releasing protein 3 in coupling phospholipase C-gamma2 to Ras in B cell receptor signaling. J Exp Med 2003;198:1841-1851.

47. Cherfils J, Chardin P. GEFs: structural basis for their activation of small GTP-binding proteins. Trends Biochem Sci 1999;24:306311.

48. Wienands J, Schweikert J, Wollscheid B, Jumaa H, Nielsen PJ, Reth M. SLP-65: a new signaling component in B lymphocytes which requires expression of the antigen receptor for phosphorylation. J Exp Med 1998; 188:791-795.

49. Fu C, Turck CW, Kurosaki T, Chan AC. BLNK: a central linker protein in B cell activation. Immunity 1998;9:93-103.

50. Engelke M, Engels N, Dittmann K, Stork B, Wienands J. $\mathrm{Ca}(2+)$ signaling in antigen receptor-activated B lymphocytes. Immunol Rev 2007;218:235-246.

51. Scharenberg AM, Humphries LA, Rawlings DJ. Calcium signalling and cell-fate choice in B cells. Nat Rev Immunol 2007;7:778789.

52. Beaulieu N, et al. Regulation of RasGRP1 by $\mathrm{B}$ cell antigen receptor requires cooperativity between three domains controlling translocation to the plasma membrane. Mol Biol Cell 2007;18:3156-3168.

53. Tognon CE, Kirk HE, Passmore LA, Whitehead IP, Der CJ, Kay RJ. Regulation of RasGRP via a phorbol ester-responsive C1 domain. Mol Cell Biol 1998;18:69957008.

54. Aiba Y, et al. Activation of RasGRP3 by phosphorylation of Thr-133 is required for B cell receptor-mediated Ras activation. Proc Natl Acad Sci USA 2004;101:1661216617.

55. Teixeira C, Stang SL, Zheng Y, Beswick NS, Stone JC. Integration of DAG signaling systems mediated by PKC-dependent phosphorylation of RasGRP3. Blood 2003; 102:1414-1420.

56. Caloca MJ, Zugaza JL, Matallanas D, Crespo P, Bustelo XR. Vav mediates Ras stimulation by direct activation of the GDP/GTP exchange factor Ras GRP1. EMBO J 2003; 22:3326-3336.

57. Coughlin JJ, Stang SL, Dower NA, Stone JC. RasGRP1 and RasGRP3 regulate B cell proliferation by facilitating $B$ cell receptor-Ras signaling. J Immunol 2005; 175:71797184.

58. Roose JP, Mollenauer M, Ho M, Kurosaki T, Weiss A. Unusual interplay of two types of Ras activators, RasGRP and SOS, establishes sensitive and robust Ras activation in lymphocytes. Mol Cell Biol 2007;27:27322745.

59. Damen JE, et al. The 145-kDa protein induced to associate with Shc by multiple cytokines is an inositol tetraphosphate and phosphatidylinositol 3,4,5-triphosphate 5-phosphatase. Proc Natl Acad Sci USA 1996;93:1689-1693.

60. Lioubin MN, Algate PA, Tsai S, Carlberg K, Aebersold A, Rohrschneider LR. p150Ship, a signal transduction molecule with inositol polyphosphate-5-phosphatase activity. Genes Dev 1996;10:1084-1095.

61. Crowley MT, Harmer SL, DeFranco AL. Activation-induced association of a $145-\mathrm{kDa}$ tyrosine-phosphorylated protein with Shc and Syk in B lymphocytes and macrophages. J Biol Chem 1996;271:11451152.

62. Kavanaugh WM, et al. Multiple forms of an inositol polyphosphate 5-phosphatase form signaling complexes with Shc and Grb2. Curr Biol 1996;6:438-445.

63. Harmer SL, DeFranco AL. The src homology domain 2-containing inositol phosphatase SHIP forms a ternary complex with Shc and Grb2 in antigen receptor-stimulated B lymphocytes. J Biol Chem 1999;274:1218312191.

64. Ingham RJ, et al. Tyrosine phosphorylation of shc in response to B cell antigen receptor engagement depends on the SHIP inositol phosphatase. J Immunol 1999;163:58915895.

65. Chacko GW, Tridandapani S, Damen JE, Liu L, Krystal G, Coggeshall KM. Negative signaling in B lymphocytes induces tyrosine phosphorylation of the $145-\mathrm{kDa}$ inositol polyphosphate 5-phosphatase, SHIP. J Immunol 1996;157:2234-2238.

66. Gupta N, et al. Negative signaling pathways of the killer cell inhibitory receptor and Fc gamma RIIb1 require distinct phosphatases. J Exp Med 1997;186:473-478.

67. Muta T, Kurosaki T, Misulovin Z, Sanchez M, Nussenzweig MC, Ravetch JV. A 13-amino-acid motif in the cytoplasmic domain of Fc gamma RIIB modulates B-cell receptor signalling. Nature 1994;368:7073.

68. Ono M, Bolland S, Tempst P, Ravetch JV. Role of the inositol phosphatase SHIP in negative regulation of the immune system by the receptor $\mathrm{Fc}_{\mathrm{c}}$ gamma)RIIB. Nature 1996;383:263-266.

69. Ono M, Okada H, Bolland S, Yanagi S, Kurosaki T, Ravetch JV. Deletion of SHIP or SHP-1 reveals two distinct pathways for inhibitory signaling. Cell 1997;90:293301.

70. DiNitto JP, Lambright DG. Membrane and juxtamembrane targeting by $\mathrm{PH}$ and PTB 
domains. Biochim Biophys Acta 2006;1761:850-867.

71. Bolland S, Pearse RN, Kurosaki T, Ravetch JV. SHIP modulates immune receptor responses by regulating membrane association of Btk. Immunity 1998;8:509-516.

72. Scharenberg AM, et al. Phosphatidylinositol-3,4,5-trisphosphate (PtdIns-3,4,5P3)/Tec kinase-dependent calcium signaling pathway: a target for SHIP-mediated inhibitory signals. EMBO J 1998;17:19611972.

73. Brauweiler A, et al. Differential regulation of B cell development, activation, and death by the Src homology 2 domain-containing 5 ' inositol phosphatase (SHIP). J Exp Med 2000;191:1545-1554.

74. Hashimoto A, Hirose K, Okada H, Kurosaki $\mathrm{T}$, Iino M. Inhibitory modulation of B cell receptor-mediated $\mathrm{Ca} 2+$ mobilization by Src homology 2 domain-containing inositol 5'-phosphatase (SHIP). J Biol Chem 1999; 274:11203-11208.

75. Kiener PA, Lioubin MN, Rohrschneider LR, Ledbetter JA, Nadler SG, Diegel ML. Co-ligation of the antigen and $\mathrm{Fc}$ receptors gives rise to the selective modulation of intracellular signaling in B cells. Regulation of the association of phosphatidylinositol 3-kinase and inositol 5'-phosphatase with the antigen receptor complex. J Biol Chem 1997;272: 3838-3844.

76. Liu Q, et al. The inositol polyphosphate 5-phosphatase ship is a crucial negative regulator of B cell antigen receptor signaling. J Exp Med 1998;188:1333-1342.

77. Okada H, et al. Role of the inositol phosphatase SHIP in B cell receptor-induced $\mathrm{Ca} 2+$ oscillatory response. J Immunol 1998;161:5129-5132.

78. Aman MJ, Lamkin TD, Okada H, Kurosaki T, Ravichandran KS. The inositol phosphatase SHIP inhibits Akt/PKB activation in B cells. J Biol Chem 1998;273:33922-33928.

79. Gold MR, et al. Targets of B-cell antigen receptor signaling: the phosphatidylinositol 3-kinase/Akt/glycogen synthase kinase-3 signaling pathway and the Rap1 GTPase. Immunol Rev 2000;176:47-68.

80. Vigorito E, Turner M. Differential requirements of PI3K subunits for BCR or BCR/CD19-induced ERK activation. Adv Exp Med Biol 2006;584:43-52.

81. Bolland S, Ravetch JV. Inhibitory pathways triggered by ITIM-containing receptors. Adv Immunol 1999;72:149-177.

82. Isnardi I, Lesourne R, Bruhns P, Fridman WH, Cambier JC, Daeron M. Two distinct tyrosine-based motifs enable the inhibitory receptor FcgammaRIIB to cooperatively recruit the inositol phosphatases SHIP1/2 and the adapters Grb2/Grap. J Biol Chem 2004;279:51931-51938.
83. Rohrschneider LR, Fuller JF, Wolf I, Liu Y, Lucas DM. Structure, function, and biology of SHIP proteins. Genes Dev 2000;14:505520.

84. Nitschke L, Tsubata T. Molecular interactions regulate $\mathrm{BCR}$ signal inhibition by CD22 and CD72. Trends Immunol 2004; 25:543-550.

85. Nitschke L. The role of CD22 and other inhibitory co-receptors in B-cell activation. Curr Opin Immunol 2005;17:290-297.

86. Otipoby KL, Draves KE, Clark EA. CD22 regulates B cell receptor-mediated signals via two domains that independently recruit Grb2 and SHP-1. J Biol Chem 2001;276: 44315-44322.

87. Yohannan J, Wienands J, Coggeshall KM, Justement LB. Analysis of tyrosine phosphorylation-dependent interactions between stimulatory effector proteins and the B cell co-receptor CD22. J Biol Chem 1999;274: 18769-18776.

88. Fusaki N, et al. BLNK is associated with the CD72/SHP-1/Grb2 complex in the WEHI231 cell line after membrane IgM cross-linking. Eur J Immunol 2000;30: 1326-1330.

89. Wu Y, et al. The B-cell transmembrane protein CD72 binds to and is an in vivo substrate of the protein tyrosine phosphatase SHP-1. Curr Biol 1998;8:1009-1017.

90. Vogel W, Ullrich A. Multiple in vivo phosphorylated tyrosine phosphatase SHP-2 engages binding to Grb2 via tyrosine 584 . Cell Growth Differ 1996; 7:1589-1597.

91. Wong L, Johnson GR. Epidermal growth factor induces coupling of protein-tyrosine phosphatase 1D to GRB2 via the $\mathrm{COOH}$-terminal SH3 domain of GRB2. J Biol Chem 1996;271:20981-20984.

92. Stork B, et al. Grb2 and the non-T cell activation linker NTAL constitute a $\mathrm{Ca}(2+)$-regulating signal circuit in B lymphocytes. Immunity 2004;21: 681-691.

93. Hashimoto A, et al. Involvement of guanosine triphosphatases and phospholipase $\mathrm{C}$-gamma 2 in extracellular signal-regulated kinase, c-Jun NH2-terminal kinase, and p38 mitogen-activated protein kinase activation by the B cell antigen receptor. J Exp Med 1998;188:1287-1295.

94. Cong F, Yuan B, Goff SP. Characterization of a novel member of the DOK family that binds and modulates Abl signaling. Mol Cell Biol 1999;19:8314-8325.

95. Lemay S, Davidson D, Latour S, Veillette A. Dok-3, a novel adapter molecule involved in the negative regulation of immunoreceptor signaling. Mol Cell Biol 2000;20:27432754.

96. Stork B, et al. Subcellular localization of Grb2 by the adaptor protein Dok-3 restricts the intensity of $\mathrm{Ca} 2+$ signaling in $\mathrm{B}$ cells. EMBO J 2007;26:1140-1149.

97. Minoo P, Zadeh MM, Rottapel R, Lebrun J-J, Ali S. A novel SHP-1/Grb2-dependent mechanism of negative regulation of cytokine receptor signaling. Blood 2004; 103 : 1398-1407.

98. Hoek KL, et al. Transitional B cell fate is associated with developmental stage-specific regulation of diacylglycerol and calcium signaling upon B cell receptor engagement. J Immunol 2006; 177:5405-5413.

99. Horejsi V, Zhang W, Schraven B. Transmembrane adaptor proteins: organizers of immunoreceptor signalling. Nat Rev Immunol 2004;4:603-616.

100. Wang Y, et al. Single and combined deletions of the NTAL/LAB and LAT adaptors minimally affect B-cell development and function. Mol Cell Biol 2005;25:44554465.

101. Engels N, et al. Recruitment of the cytoplasmic adaptor Grb2 to surface IgG and IgE provides antigen receptor-intrinsic costimulation to class-switched B cells. Nat Immunol 2009;10:1018-1025.

102. Horikawa K, et al. Enhancement and suppression of signaling by the conserved tail of IgG memory-type B cell antigen receptors. J Exp Med 2007;204: 759-769.

103. Kaisho T, Schwenk F, Rajewsky K. The roles of gamma 1 heavy chain membrane expression and cytoplasmic tail in IgG1 responses. Science 1997;276:412-415.

104. Martin SW, Goodnow CC. Burst-enhancing role of the IgG membrane tail as a molecular determinant of memory. Nat Immunol 2002;3:182-188.

105. Waisman A, et al. IgG1 B cell receptor signaling is inhibited by $\mathrm{CD} 22$ and promotes the development of B cells whose survival is less dependent on Ig alpha/beta. J Exp Med 2007;204:747-758.

106. Grabbe A, Wienands J. Human SLP-65 isoforms contribute differently to activation and apoptosis of B lymphocytes. Blood 2006;108:3761-3768.

107. Tolar P, Sohn HW, Pierce SK. The initiation of antigen-induced B cell antigen receptor signaling viewed in living cells by fluorescence resonance energy transfer. Nat Immunol 2005;6:1168-1176.

108. Brooks SR, Kirkham PM, Freeberg L, Carter RH. Binding of cytoplasmic proteins to the CD19 intracellular domain is high affinity, competitive, and multimeric. J Immunol 2004; 172:7556-7564.

109. Brooks SR, Li X, Volanakis EJ, Carter RH. Systematic analysis of the role of CD19 cytoplasmic tyrosines in enhancement of activation in Daudi human B cells: clustering of phospholipase $\mathrm{C}$ and Vav and of Grb2 and 
Sos with different CD19 tyrosines. J Immunol 2000;164:3123-3131.

110. Rickert RC. Regulation of B lymphocyte activation by complement $\mathrm{C} 3$ and the $\mathrm{B}$ cell coreceptor complex. Curr Opin Immunol 2005; 17:237-243.

111. Engel P, Zhou LJ, Ord DC, Sato S, Koller B, Tedder TF. Abnormal B lymphocyte development, activation, and differentiation in mice that lack or overexpress the CD19 signal transduction molecule. Immunity 1995;3:39-50.

112. Rickert RC, Rajewsky K, Roes J. Impairment of T-cell-dependent B-cell responses and B1 cell development in CD19-deficient mice. Nature 1995;376:352-355.

113. Salzer U, Grimbacher B. Common variable immunodeficiency: the power of co-stimulation. Semin Immunol 2006;18:337-346.

114. Tedder TF, Poe JC, Fujimoto M, Haas KM, Sato $\mathrm{S}$. The CD19-CD21 signal transduction complex of B lymphocytes regulates the balance between health and autoimmune disease: systemic sclerosis as a model system. Curr Dir Autoimmun 2005;8:55-90.

115. Fujikawa K, et al. Vav1/2/3-null mice define an essential role for Vav family proteins in lymphocyte development and activation but a differential requirement in MAPK signaling in T and B cells. J Exp Med 2003;198:1595-1608.

116. Depoil D, et al. CD19 is essential for B cell activation by promoting $\mathrm{B}$ cell receptorantigen microcluster formation in response to membrane-bound ligand. Nat Immunol 2008;9:63-72.

117. Weber M, et al. Phospholipase C-gamma2 and Vav cooperate within signaling microclusters to propagate B cell spreading in response to membrane-bound antigen. J Exp Med 2008;205:853-868.

118. Arana E, et al. Activation of the small GTPase Rac2 via the B cell receptor regulates $B$ cell adhesion and immunological-synapse formation. Immunity 2008;28:88-99.

119. Vigorito E, Kovesdi D, Turner M. Synergistic activation of PKD by the B cell antigen receptor and $\mathrm{CD} 19$ requires PI3K, Vav1 and PLCgamma. Cell Signal 2006;18:14551460.

120. Inabe K, Kurosaki T. Tyrosine phosphorylation of B-cell adaptor for phosphoinositide 3-kinase is required for Akt activation in response to CD19 engagement. Blood 2002;99:584-589.

121. Okada T, Maeda A, Iwamatsu A, Gotoh K, Kurosaki T. BCAP: the tyrosine kinase substrate that connects B cell receptor to phosphoinositide 3-kinase activation. Immunity 2000;13:817-827.

122. Aiba Y, Kameyama M, Yamazaki T, Tedder TF, Kurosaki T. Regulation of B-cell development by BCAP and CD19 through their binding to phosphoinositide 3-kinase.

Blood 2008;111:1497-1503.

123. Nishida M, et al. Novel recognition mode between Vav and Grb2 SH3 domains. EMBO J 2001;20:2995-3007.

124. Ramos-Morales F, et al. The proline-rich region of Vav binds to Grb2 and Grb3-3. Oncogene 1995;11:1665-1669.

125. Ye ZS, Baltimore D. Binding of Vav to Grb2 through dimerization of Src homology 3 domains. Proc Natl Acad Sci USA 1994;91: 12629-12633.

126. Johmura S, et al. Regulation of Vav localization in membrane rafts by adaptor molecules Grb2 and BLNK. Immunity 2003; 18: 777-787.

127. Ong SE, et al. Stable isotope labeling by amino acids in cell culture, SILAC, as a simple and accurate approach to expression proteomics. Mol Cell Proteomics 2002;1: 376-386.

128. Blagoev B, Kratchmarova I, Ong SE, Nielsen M, Foster LJ, Mann M. A proteomics strategy to elucidate functional protein-protein interactions applied to EGF signaling. Nat Biotechnol 2003;21:315-318.

129. Oellerich T, Gronborg M, Neumann K, Hsiao HH, Urlaub H, Wienands J. SLP-65 phosphorylation dynamics reveals a functional basis for signal integration by receptor-proximal adaptor proteins. Mol Cell Proteomics 2009;8:1738-1750.

130. Cox J, Mann M. MaxQuant enables high peptide identification rates, individualized p.p.b.-range mass accuracies and proteomewide protein quantification. Nat Biotechnol 2008;26:1367-1372.

131. Cox J, et al. A practical guide to the MaxQuant computational platform for SILAC-based quantitative proteomics. Nat Protoc 2009;4:698-705.

132. den Hertog J, Tracy S, Hunter T. Phosphorylation of receptor protein-tyrosine phosphatase alpha on Tyr789, a binding site for the SH3-SH2-SH3 adaptor protein GRB-2 in vivo. EMBO J 1994;13:3020-3032.

133. Su J, Batzer A, Sap J. Receptor tyrosine phosphatase R-PTP-alpha is tyrosine-phosphorylated and associated with the adaptor protein Grb2. J Biol Chem 1994;269:18731-19834.

134. Veillette A, Rhee I, Souza CM, Davidson D. PEST family phosphatases in immunity, autoimmunity, and autoinflammatory disorders. Immunol Rev 2009;228:312-324.

135. Huang F, Gu H. Negative regulation of lymphocyte development and function by the Cbl family of proteins. Immunol Rev 2008;224:229-238.

136. Kitaura Y, et al. Control of the B cell-intrinsic tolerance programs by ubiquitin ligases Cbl and Cbl-b. Immunity 2007;26:567578.
137. Ota $\mathrm{S}$, et al. The RING finger domain of $\mathrm{Cbl}$ is essential for negative regulation of the Syk tyrosine kinase. J Biol Chem 2000;275: 414-422.

138. Rao N, et al. The non-receptor tyrosine kinase Syk is a target of Cbl-mediated ubiquitylation upon B-cell receptor stimulation. EMBO J 2001;20:7085-7095.

139. Sohn HW, Gu H, Pierce SK. Cbl-b negatively regulates $\mathrm{B}$ cell antigen receptor signaling in mature B cells through ubiquitination of the tyrosine kinase Syk. J Exp Med 2003;197: 1511-1524.

140. Dragone LL, et al. Src-like adaptor protein (SLAP) regulates B cell receptor levels in a c-Cbl-dependent manner. Proc Natl Acad Sci USA 2006;103:18202-18207.

141. Panchamoorthy G, et al. p120cbl is a major substrate of tyrosine phosphorylation upon $B$ cell antigen receptor stimulation and interacts in vivo with Fyn and Syk tyrosine kinases, Grb2 and Shc adaptors, and the p 85 subunit of phosphatidylinositol 3-kinase. J Biol Chem 1996;271:3187-3194.

142. Yankee TM, Solow SA, Draves KD, Clark EA. Expression of the Grb2-related protein of the lymphoid system in B cell subsets enhances B cell antigen receptor signaling through mitogen-activated protein kinase pathways. J Immunol 2003;170:349-355.

143. Donovan JA, Wange RL, Langdon WY, Samelson LE. The protein product of the c-cbl protooncogene is the $120-\mathrm{kDa}$ tyrosine-phosphorylated protein in Jurkat cells activated via the $\mathrm{T}$ cell antigen receptor. J Biol Chem 1994;269:22921-22924.

144. Meisner H, Conway BR, Hartley D, Czech MP. Interactions of $\mathrm{Cbl}$ with Grb2 and phosphatidylinositol 3'-kinase in activated Jurkat cells. Mol Cell Biol 1995;15:35713578.

145. Keshava Prasad TS, et al. Human Protein Reference Database-2009 update. Nucleic Acids Res 2009;37:D767-D772.

146. Hermjakob H, et al. IntAct: an open source molecular interaction database. Nucleic Acids Res 2004;32:D452-D455.

147. Cheng AM, et al. Mammalian Grb2 regulates multiple steps in embryonic development and malignant transformation. Cell 1998;95:793-803.

148. Ware MD, Rosten P, Damen JE, Liu L, Humphries RK, Krystal G. Cloning and characterization of human SHIP, the $145-\mathrm{kD}$ inositol 5-phosphatase that associates with SHC after cytokine stimulation. Blood 1996;88:2833-2840.

149. Honma M, et al. Dok-3 sequesters Grb2 and inhibits the Ras-Erk pathway downstream of protein-tyrosine kinases. Genes Cells 2006;11:143-151.

150. Chardin P, et al. Human Sos 1 : a guanine nucleotide exchange factor for Ras that 
binds to GRB2. Science 1993;260:13381343.

151. Houtman JC, et al. Oligomerization of signaling complexes by the multipoint binding of GRB2 to both LAT and SOS1. Nat Struct Mol Biol 2006;13:798-805.

152. Yoon SY, Koh WS, Lee MK, Park YM, Han MY. Dynamin II associates with Grb2 SH3 domain in Ras transformed NIH3T3 cells. Biochem Biophys Res Commun 1997;234: 539-543.

153. Anafi M, Kiefer F, Gish GD, Mbamalu G, Iscove NN, Pawson T. SH2/SH3 adaptor proteins can link tyrosine kinases to a Ste20related protein kinase, HPK1. J Biol Chem 1997;272:27804-27811.

154. Oehrl W, et al. The germinal center kinase (GCK)-related protein kinases HPK1 and KHS are candidates for highly selective signal transducers of Crk family adapter proteins. Oncogene 1998;17:1893-1901.

155. Liou J, et al. HPK1 is activated by lymphocyte antigen receptors and negatively regulates AP-1. Immunity 2000; 12:399-408.

156. Smit L, van der Horst G, Borst J. Formation of Shc/Grb2- and Crk adaptor complexes containing tyrosine phosphorylated $\mathrm{Cbl}$ upon stimulation of the B-cell antigen receptor. Oncogene 1996;13:381-389.

157. Wu C, et al. Systematic identification of SH3 domain-mediated human protein-protein interactions by peptide array target screening. Proteomics 2007;7:1775-1785.

158. Scholler JK, Perez-Villar JJ, O’Day K, Kanner $\mathrm{SB}$. Engagement of the T lymphocyte antigen receptor regulates association of son-ofsevenless homologues with the SH3 domain of phospholipase Cgamma1. Eur J Immunol 2000;30:2378-2387.
159. Yang SS, Van Aelst L, Bar-Sagi D. Differential interactions of human Sos1 and Sos2 with Grb2. J Biol Chem 1995;270:1821218215.

160. Elly C, et al. Tyrosine phosphorylation and complex formation of Cbl-b upon T cell receptor stimulation. Oncogene 1999;18:1147-1156.

161. Ettenberg SA, et al. cbl-b inhibits epidermal growth factor receptor signaling. Oncogene 1999;18:1855-1866.

162. den Hertog J, Hunter T. Tight association of GRB2 with receptor protein-tyrosine phosphatase alpha is mediated by the $\mathrm{SH} 2$ and Cterminal SH3 domains. EMBO J 1996;15: 3016-3027.

163. Charest A, Wagner J, Kwan M, Tremblay ML. Coupling of the murine protein tyrosine phosphatase PEST to the epidermal growth factor (EGF) receptor through a $\mathrm{Src}$ homology 3 (SH3) domain-mediated association with Grb2. Oncogene 1997;14: 1643-1651.

164. Wheeler M, Domin J. Recruitment of the class II phosphoinositide 3-kinase C2beta to the epidermal growth factor receptor: role of Grb2. Mol Cell Biol 2001;21:66606667.

165. Wang J, Auger KR, Jarvis L, Shi Y, Roberts TM. Direct association of Grb2 with the p 85 subunit of phosphatidylinositol 3-kinase. J Biol Chem 1995;270:12774-12780.

166. Itoh S, et al. Adapter molecule Grb2-associated binder 1 is specifically expressed in marginal zone B cells and negatively regulates thymus-independent antigen-2 responses. J Immunol 2002;168:51105116.

167. Holgado-Madruga M, Emlet DR, Moscatello DK, Godwin AK, Wong AJ. A Grb2-associ- ated docking protein in EGF- and insulinreceptor signalling. Nature 1996;379:560564.

168. Ramos-Morales F, Druker BJ, Fischer S. Vav binds to several $\mathrm{SH} 2 / \mathrm{SH} 3$ containing proteins in activated lymphocytes. Oncogene 1994;9:1917-1923.

169. Saci A, Liu WQ, Vidal M, Garbay C, Rendu F, Bachelot-Loza C. Differential effect of the inhibition of Grb2-SH3 interactions in platelet activation induced by thrombin and by Fc receptor engagement. Biochem J 2002;363: 717-725.

170. Momose H, et al. Dual phosphorylation of phosphoinositide 3-kinase adaptor Grb2associated binder 2 is responsible for superoxide formation synergistically stimulated by Fc gamma and formyl-methionyl-leucylphenylalanine receptors in differentiated THP-1 cells. J Immunol 2003;171:42274234.

171. Koonpaew S, Janssen E, Zhu M, Zhang W. The importance of three membrane-distal tyrosines in the adaptor protein NTAL/LAB. J Biol Chem 2004;279:11229-11235.

172. Zhu M, Janssen E, Leung K, Zhang W. Molecular cloning of a novel gene encoding a membrane-associated adaptor protein (LAX) in lymphocyte signaling. J Biol Chem 2002;277:46151-46158.

173. Liu Y, Zhang W. Identification of a new transmembrane adaptor protein that constitutively binds Grb2 in B cells. J Leukoc Biol 2008;84:842-851.

174. Takemoto Y, Furuta M, Sato M, Findell PR, Ramble W, Hashimoto Y. Growth factor receptor-bound protein 2 (Grb2) association with hemopoietic specific protein 1 : linkage between Lck and Grb2. J Immunol 1998;161:625-630. 